\title{
Conversion to generic cyclosporine $A$ in stable chronic patients after heart transplantation
}

This article was published in the following Dove Press journal:

Drug Design, Development and Therapy

27 November 2013

Number of times this article has been viewed

\author{
Maximilian Kraeuter' \\ Matthias Helmschrott ${ }^{1}$ \\ Christian Erbel' \\ Christian A Gleissner' \\ Lutz Frankenstein' \\ Bastian Schmack ${ }^{2}$ \\ Arjang Ruhparwar ${ }^{2}$ \\ Philipp Ehlermann' \\ Hugo A Katus' \\ Andreas O Doesch' \\ 'Department of Cardiology, \\ ${ }^{2}$ Department of Cardiac Surgery, \\ University of Heidelberg, Heidelberg, \\ Germany
}

Correspondence: Andreas O Doesch Medizinische Klinik III, Kardiologie, Angiologie and Pneumologie, Ebene 00, Im Neuenheimer Feld 410, 69120

Heidelberg, Germany

Tel +49622I 5639936

Fax +496221564105

Email andreas.doesch@med.uni-

heidelberg.de
Background: Cyclosporine A (CSA) is a narrow therapeutic index drug. Available CSA products differ in the constitution of their emulsion. To compare intra-individual differences after a conversion to a generic CSA, a retrospective single-center study was initiated.

Methods: Twenty adult stable chronic ( $>24$ months post heart transplant) recipients were included in the present retrospective study. These patients were previously switched from Sandimmune Neoral ${ }^{\circledR}$ to the generic CSA $\left(\right.$ Equoral $\left.^{\circledR}\right)$ according to the patients' preference during the clinical routine. Dose-normalized trough levels (DNL) and trough levels (C0) at 8 months, 4 months, and 2 weeks before the switch were retrospectively compared with the corresponding values at 2 weeks, 4 months, and 8 months after the switch to the generic CSA. Additionally, changes in the routine laboratory parameters, the number of treated rejection episodes, and the adherence to the CSA target levels were compared.

Results: The mean DNL (adapted to the daily CSA dose in $\mathrm{mg}$ ) was $0.71 \pm 0.26(\mathrm{ng} / \mathrm{mL}) / \mathrm{mg}$ on Neoral therapy; on Equoral it was $0.68 \pm 0.23(\mathrm{ng} / \mathrm{mL}) / \mathrm{mg},(P=0.38)$. In comparison to the CSA daily dose prior to the conversion, at postconversion, no significant changes of CSA daily dose were observed (Neoral 140.67 $\pm 39.81 \mathrm{mg}$ versus Equoral $134.58 \pm 41.61 \mathrm{mg} ; P=0.13$ ). No rejection episodes requiring therapy occurred prior to or postconversion $(P=0.99)$. Additionally, no statistically significant changes of routine laboratory parameters regarding the Modification of Diet in Renal Disease or hematological parameters were seen (all $P=$ not significant). No adverse events after the conversion were observed.

Conclusion: This study in chronic and stable HTx patients demonstrated no statistically significant differences in the CSA DNL after a conversion to generic CSA (Equoral). The generic CSA was generally well-tolerated. We concluded that a conversion from Neoral to Equoral is safe and clinically feasible in this distinct patient population. However, multiple switches between different generic immunosuppressants must especially be avoided in the interest of patient safety, and close follow-up examinations must be warranted.

Keywords: heart transplantation, immunosuppression, generic cyclosporine A

\section{Introduction}

Long-term immunosuppression is essential for allograft survival. Introduced in 1983, cyclosporine A (CSA) is an immunosuppressive agent used to prevent allograft rejection. CSA is a cyclic nonribosomal lipophilic peptide of eleven amino acids. ${ }^{1}$ Therapeutic success and efficiency depend eminently on the intestinal absorption of each different CSA formulation. ${ }^{2}$ In previous studies, differences regarding the pharmacokinetic and the pharmacodynamic quality between the currently available CSA formulations have been found. ${ }^{2}$ However, in stable adult patients after renal transplantation, Vítko et al demonstrated a safe interchangeability of Sandimmune 
Neoral $^{\circledR}$ (Novartis Pharmaceuticals Corporation, East Hanover, NJ, USA) and Equoral ${ }^{\circledR}$ (Teva Pharmaceutical Industries, Ltd, Petah Tikva, Israel). ${ }^{3}$ Additionally, in a 5-year follow-up analysis of stable renal transplant recipients, Equoral had a comparable 5-year patient and graft survival and effectively prevented acute rejection episodes. ${ }^{4}$ However, no comparable data exist in patients after heart transplantation (HTx). A PubMed literature search was performed on March 11, 2013. We used the keywords "cyclosporine A", "heart transplantation", and "generic". Therefore, a singlecenter study was performed retrospectively to compare CSA trough levels and dose-normalized predose levels (DNL) in stable HTx patients after a conversion from Neoral to generic Equoral. Additionally, the changes in the routine laboratory parameters, the number of treated rejection episodes, and the adherence to the CSA target levels were analyzed.

\section{Patients and methods}

Included in this retrospective single-center study were clinically stable chronic HTx patients (ie, $>24$ months post-HTx), who had been switched to the generic CSA (Equoral) during clinical routine according to the patients' preference.

Patients transplanted from 1989 to April 2009 were included in this study. All study patients were routinely monitored at the Heidelberg HTx Center according to the Center's clinical routine protocol. The dose-adapted trough levels (DNL) were chosen as the main target parameter to compare the CSA trough levels under different CSA doses.

According to the Center's routine protocol, no rejection episodes requiring therapy or acute infections were present at the conversion. Additionally, routine exclusion criteria were pregnancy, multiple organ transplantation, and a lack of adherence according to the investigators' discretion. All patients gave their written informed consent prior to study inclusion. The study was approved by the ethics committee of the University of Heidelberg and was performed in accordance with the ethical standards laid down in the 2008 Declaration of Helsinki. Rejection episodes were graduated according to the revised International Society for Heart and Lung Transplantation Classification of $2005 .^{5}$
Laboratory analysis of CSA trough level was performed in-house according to the Center's routine protocols. The ethylenediaminetetraacetic acid blood was drawn 1 hour before the morning intake of the CSA medication. An analysis was performed using a validated liquid chromatography-tandem mass spectrometry assay, excluding the measurement of CSA metabolites. At the Heidelberg HTx Center, the CSA is routinely given as part of a usually dual immunosuppressive regimen. ${ }^{6}$ Steroids are routinely withdrawn 6 months postHTx at the investigators' discretion whenever clinically feasible. Routine CSA target levels for stable chronic patients are $70-90 \mathrm{ng} / \mathrm{dL}$ for CSA in combination with mycophenolate mofetil, 50-70 ng/dL in combination with everolimus, and 100-125 ng/dL in combination with azathioprine.

The CSA trough levels (Neoral) at baseline, 4 months, and 8 months before conversion were compared to the respective generic CSA trough levels at 2 weeks, 4 months, and 8 months after conversion (Figure 1). All the clinical and routine parameters were acquired during the clinical routine. If necessary, the CSA dosage was adjusted according to the investigators' discretion. To keep CSA blood levels comparable under different CSA dosages, the ratio of the CSA trough level $(\mathrm{C} 0)$ to the daily CSA dose (= DNL $[\mathrm{ng} / \mathrm{mL}] / \mathrm{mg}$ ) was used. Myocardial biopsies were performed weekly during the first month post-HTx, biweekly during the second month, once a month until month 6 , and bimonthly until month 12 post-HTx. Thereafter, myocardial biopsies were performed in biyearly intervals. According to the local clinical routine, all patients received a biopsy 4 months after the switch.

\section{Statistical analysis}

Statistical analysis was performed using the Statistical Package for the Social Science software (version 14.0, SPSS Inc, Chicago, IL, USA). A two-sided $P$-value of $<0.05$ was considered to be statistically significant. The Student's $t$-test was used for normally distributed variables; the Mann-Whitney test and the Wilcoxon signed-rank test were used for the other variables. Categorical variables were compared using the Fisher's exact test.



Figure I Study timeline with time points of clinical and laboratory assessments under Neoral (before switch) and Equoral (after switch). Abbreviation: $\mathrm{C} 0$, trough level. 
Table I Patient characteristics $(n=20)$

\begin{tabular}{ll}
\hline Patient number, $\mathrm{n}$ & 20 \\
Sex male/female, $\mathrm{n}(\%)$ & $13(65.0 \%) / 7(35.0 \%)$ \\
Initial cardiac diagnosis, $\mathrm{n}(\%)$ & $\bullet$ Dilated cardiomyopathy, I0 (50.0\%) \\
& - Ischemic cardiomyopathy, $6(30.0 \%)$ \\
& - Transthyretin-amyloidosis, 2 (10.0\%) \\
& - Congenital aortic coarctation, I (5.0\%) \\
& $\bullet$ Valvular cardiomyopathy, I (5.0\%) \\
\hline
\end{tabular}

Abbreviation: $\mathrm{n}$, number of patients.

\section{Results}

\section{Patients}

Included in the present study were seven female $(35.0 \%$ of total) and 13 male patients ( $65.0 \%$ of total). The mean patients' age 8 months prior to the switch was $60.7 \pm 10.0$ years (range 45.2-77.5 years; median, 61.0 years). The mean time post-HTx was $10.0 \pm 5.0$ years (range 3.7-23.6 years; median, 8.0 years). Further patient parameters are given in Table 1.

\section{Immunosuppression}

Of the 20 patients included in the present study, 13 (65.0\% of total) had CSA in combination with mycophenolate mofetil, four (20.0\% of total) in combination with everolimus, two (10.0\% of total) in combination with azathioprine, and one patient $(5.0 \%$ of total) in combination with steroids only.

\section{Dose-normalized level}

The main target parameter was the change in the CSA DNL under Equoral in comparison to Neoral (Figure 2). On the
Neoral therapy, the mean DNL was $0.71 \pm 0.26(\mathrm{ng} / \mathrm{mL}) / \mathrm{mg}$ compared to $0.68 \pm 0.23(\mathrm{ng} / \mathrm{mL}) / \mathrm{mg}$ on Equoral $(P=0.38)$ (Table 2). Neoral DNL showed a $95 \%$ confidence interval (CI) of 0.64 to $0.77(\mathrm{ng} / \mathrm{mL}) / \mathrm{mg}$. The $95 \%$ CI of Equoral was 0.62 to $0.73(\mathrm{ng} / \mathrm{mL}) / \mathrm{mg}(P=0.38)$. The paired values of DNL at 4 months $(P=0.52)$ and at 8 months $(P=0.19)$ pre- and postconversion showed no significant difference.

The DNL $(P=0.84)$ and the CSA C0 levels $(P=0.60)$ at 8 months and 4 months prior to the conversion did not demonstrate a significant statistical difference (Tables 3 and 4). Accordingly, the DNL $(P=0.57)$ and the CSA C0 levels $(P=0.23)$ at 4 months and 8 months postconversion also did not demonstrate a significant statistical difference (Tables 5 and 6).

\section{Cyclosporine A}

Two weeks after the switch, the CSA C0 levels were not within the target range in eight patients ( $40 \%$ of total), making an adjustment of Equoral dosage necessary. One week later (at the next consecutive measurement), all these patients were within the target range.

Comparing therapeutic adjustments of the daily CSA dose after the switch to the generic CSA, 12 patients $(60.0 \%)$ received a reduction of daily CSA dose within 8 months after the switch and five patients $(25.0 \%)$ received a higher daily dose to stay within the targeted therapeutic blood levels. Three patients (15.0\%) kept their mean daily CSA dose unchanged. Overall, after the conversion to generic CSA, the mean daily CSA dose was reduced about $4.33 \%$.

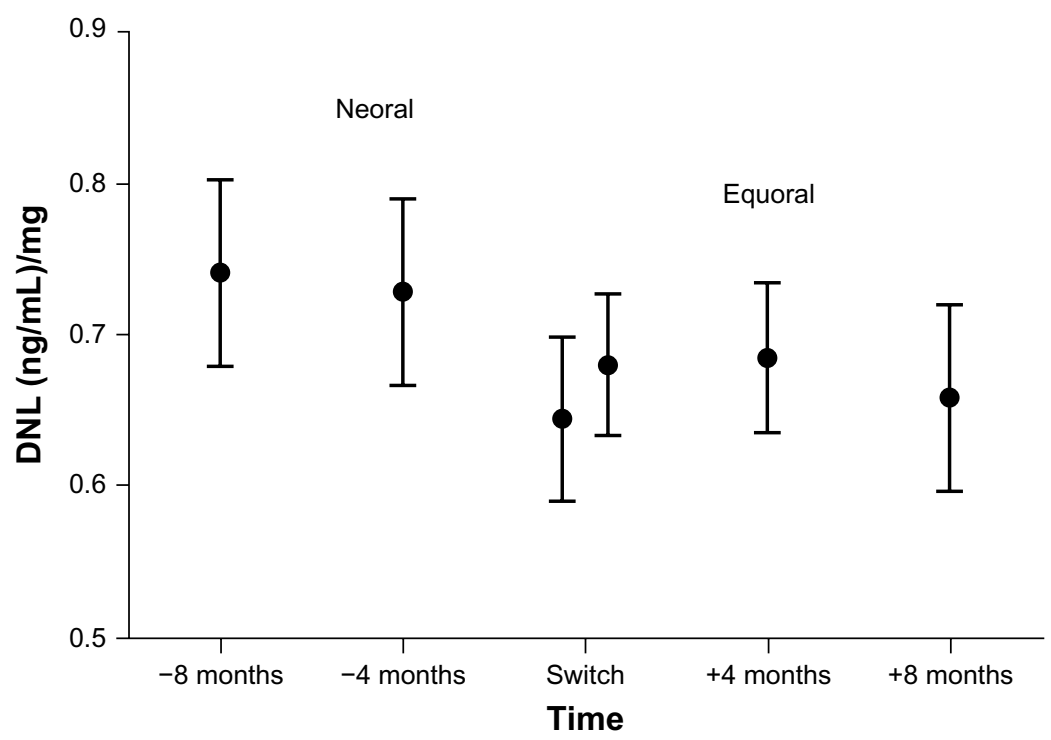

Figure 2 Mean DNL and 95\% confidence interval in all patients under Neoral and Equoral.

Note: Switch: time point of conversion from Neoral to Equoral.

Abbreviation: DNL, dose-normalized predose level. 
Table 2 Pre- and postconversion

\begin{tabular}{lll}
\hline & Neoral & Equoral \\
\hline Graft survival, $\mathrm{n}(\%)$ & $20(\mathrm{I} 00.0)$ & $20(\mathrm{I} 00.0)$ \\
Patient survival, $\mathrm{n}(\%)$ & $20(\mathrm{I} 00.0)$ & $20(\mathrm{I} 00.0)$ \\
Mean daily CSA dose, $\mathrm{mg}(\mathrm{SD})$ & $\mathrm{I} 40.67(39.8 \mathrm{I})$ & $\mathrm{I} 34.58(4 \mathrm{I} .6 \mathrm{I})$ \\
Mean DNL, (ng/mL)/mg (SD) & $0.7 \mathrm{I}(0.26)$ & $0.68(0.23)$ \\
Lower 95\% Cl of DNL & 0.64 & 0.62 \\
Upper 95\% Cl of DNL & 0.77 & 0.73 \\
\hline
\end{tabular}

Abbreviations: $n$, number of patients; CSA, cyclosporine $\mathrm{A} ; \mathrm{SD}$, standard deviation; $\mathrm{Cl}$, confidence interval; $\mathrm{DNL}$, dose-normalized predose level.

Table 3 Differences in DNL on Neoral before switch

\begin{tabular}{llll}
\hline Neoral & $\begin{array}{l}\mathbf{8} \text { months } \\
\text { before switch }\end{array}$ & $\begin{array}{l}\text { 4 months } \\
\text { before switch }\end{array}$ & P-value \\
\hline Mean DNL & 0.74 & 0.73 & 0.84 \\
SD & 0.27 & 0.27 & \\
Minimum DNL & 0.37 & 0.39 & \\
Maximum DNL & 1.31 & 1.33 & \\
Median DNL & 0.74 & 0.70 & \\
\hline
\end{tabular}

Abbreviations: DNL, dose-normalized level; SD, standard deviation.

Table 4 Differences in C0 (ng/mL) level on Neoral before switch

\begin{tabular}{llll}
\hline Neoral & $\begin{array}{l}\mathbf{8} \text { months } \\
\text { before switch }\end{array}$ & $\begin{array}{l}\text { 4 months } \\
\text { before switch }\end{array}$ & P-value \\
\hline Mean C0 & 102.2 & 97.2 & 0.60 \\
SD & 39.6 & 31.3 & \\
Minimum C0 & 55.0 & 58.0 & \\
Maximum C0 & 197.0 & 164.0 & \\
Median C0 & 94.0 & 90.0 & \\
\hline
\end{tabular}

Abbreviations: $\mathrm{C} 0$, trough level; SD, standard deviation.

Table 5 Differences in DNL on Equoral after switch

\begin{tabular}{llll}
\hline Equoral & $\begin{array}{l}\text { 4 months } \\
\text { after switch }\end{array}$ & $\begin{array}{l}\mathbf{8} \text { months } \\
\text { after switch }\end{array}$ & P-value \\
\hline Mean DNL & 0.69 & 0.66 & 0.57 \\
SD & 0.22 & 0.27 & \\
Minimum DNL & 0.40 & 0.24 & \\
Maximum DNL & 1.14 & 1.31 & \\
Median DNL & 0.64 & 0.65 & \\
\hline
\end{tabular}

Abbreviations: DNL, dose-normalized predose level; SD, standard deviation.

Table 6 Differences in C0 (ng/mL) level on Equoral after the switch

\begin{tabular}{llll}
\hline Equoral & $\begin{array}{l}\text { 4 months } \\
\text { after switch }\end{array}$ & $\begin{array}{l}\mathbf{8} \text { months } \\
\text { after switch }\end{array}$ & P-value \\
\hline Mean C0 & 87.0 & 79.7 & 0.23 \\
SD & 26.3 & 24.9 & \\
Minimum C0 & 51.0 & 32.0 & \\
Maximum C0 & 143.0 & 127.0 & \\
Median C0 & 90.0 & 79.0 & \\
\hline
\end{tabular}

Abbreviations: $\mathrm{C} 0$, trough level; SD, standard deviation.
However, the level of the statistical significance was not reached ( $140.67 \pm 39.81 \mathrm{mg}$ versus $134.58 \pm 41.61 \mathrm{mg} ; P=0.13$; Figure 3).

\section{Adverse events}

During the study period, no rejection episodes requiring therapy were observed $(P=0.99)$. No adverse events or side effects were observed. No significant changes in the routine laboratory test regarding the Modification of Diet in Renal Disease (MDRD) or hematologic parameters were seen (Table 7). During a follow-up period, the patient survival was $100.0 \%$ after the switch to a generic CSA.

\section{Discussion}

The use of generic immunosuppressants in patients after solid organ transplantation is of eminent interest. In patients after renal transplantation, promising study data are available, showing comparable daily cyclosporine doses and levels after the switch to a generic CSA, without significant differences regarding adverse events. ${ }^{7}$ However, available study data in patients after HTx are extremely limited. Therefore, we performed a retrospective analysis in 20 stable chronic HTx recipients, who were switched from Neoral to Equoral during their clinical routine and were routinely followed-up at the Heidelberg HTx Center.

The adaption of the patients' daily dose intake on the measured trough levels was an issue in our clinical comparison of the different CSA formulations. Therefore, we used the DNL ([ng/mL]/mg) as the main target parameter to account for the dosage changes during the clinical follow-up and to compare data even after dose adaption. Regarding the feasibility in a routine clinical setting, the CSA C0 levels - not the CSA blood level 2 hours after the morning dose (C2) levels - were used for the DNL calculation, due to the fact that the CSA C2 monitoring does not improve recipient management. ${ }^{8}$

Most importantly, our data demonstrate the feasibility of a 1:1 switch between Neoral and Equoral in this distinctive patient cohort showing comparable DNL before and after the switch. Routine laboratory values showed no statistically significant differences of hematological or renal function parameters (MDRD) after the switch. Immediately after the switch, $40.0 \%$ of the patients were not within the admittedly narrow target range making an Equoral dose adjustment necessary. However, at the next consecutive measurement, target levels were reached in all of these patients, underlining the importance of close and standardized follow-up strategies and excellent patient adherence. 


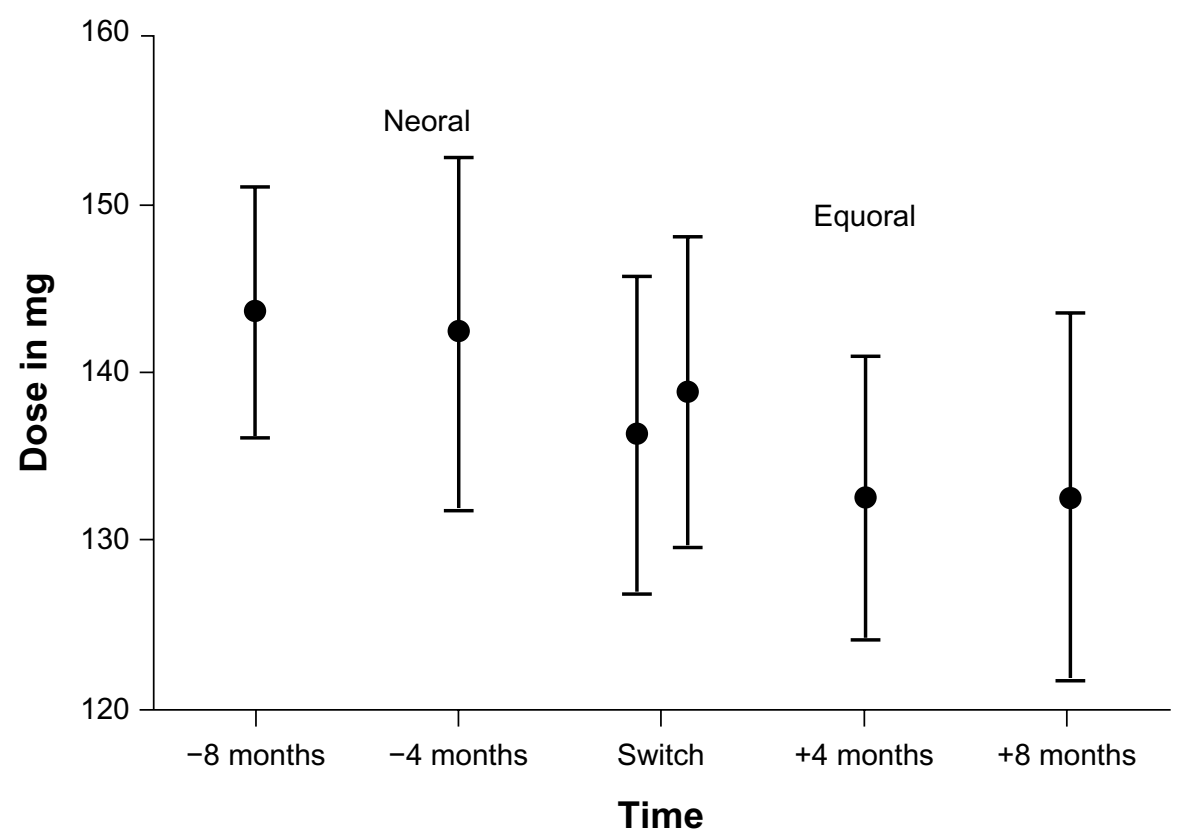

Figure 3 Corresponding values of mean cyclosporine dose and $95 \%$ confidence interval in all patients under Neoral and Equoral. Note: Switch: time point of conversion from Neoral to Equoral.

One of our main concerns in the clinical routine was the prevention of rejection episodes. Patients received close follow-up examinations according to the local clinical routine to identify signs of rejections as early as possible, including a routine biopsy 4 months after the switch. All patients were clinically stable before and after the switch and had no rejection episodes requiring medical therapy in the 8-month period before and after the switch to the generic CSA.

However, the data published by Helderman et al showed differences in the total health care costs in spite of positive tested bioequivalence. ${ }^{9}$ They concluded that the patients who received the generic CSA may need higher doses to maintain the transplanted organ than the patients who received branded CSA. ${ }^{9}$ This is in contrast to our clinical findings, which showed that the CSA dose in mg was not significantly different after the switch. Our results are backed by renal transplant recipients showing a safe interchangeability.
In conclusion, our results show no statistically significant differences in clinically important parameters after conversion to Equoral. In chronic, stable patients after HTxs, switch to generic CSA was possible in a routine outpatient setting.

\section{Limitations}

Our single-center pilot study is limited by the relatively small patient number of 20 participants. However, currently available data in patients after HTx are extremely limited. The results of this single-center pilot study in chronic HTx recipients are promising. Monitoring of the CSA C2 levels was explicitly not used, due to the limited feasibility in the clinical routine; no additional clinical benefit has been demonstrated for $\mathrm{C} 2$ monitoring previously. ${ }^{10}$ Future blinded large multicenter studies are required to confirm these findings in chronic and de novo patients after HTx and to evaluate longterm effects in terms of survival.

Table 7 Routine laboratory

\begin{tabular}{|c|c|c|c|c|c|c|c|c|}
\hline & \multicolumn{2}{|c|}{ Baseline } & \multicolumn{3}{|c|}{4 months after switch } & \multicolumn{3}{|c|}{8 months after switch } \\
\hline & Mean & SD & Mean & SD & $P$-value* & Mean & SD & P-value* \\
\hline $\mathrm{Hb}$ g/dL & 12.88 & 1.68 & 13.02 & 1.81 & 0.45 & 12.82 & 1.55 & 0.66 \\
\hline Leucocytes/nL & 5.79 & 1.60 & 5.92 & 1.49 & 0.65 & 6.18 & 1.95 & 0.28 \\
\hline Thrombocytes/nL & 214.10 & 67.82 & 215.25 & 61.59 & 0.88 & 213.05 & 72.29 & 0.89 \\
\hline Creatinine $\mathrm{mg} / \mathrm{dL}$ & 1.28 & 0.33 & 1.30 & 0.33 & 0.63 & 1.27 & 0.37 & 0.96 \\
\hline MDRD mL/minute $* 1.73 \mathrm{~m}^{2}$ & 59.93 & 21.98 & 59.57 & 20.23 & 0.54 & 59.57 & 20.23 & 0.89 \\
\hline
\end{tabular}

Note: *Versus baseline.

Abbreviations: $\mathrm{Hb}$, hemoglobin; MDRD, Modification of Diet in Renal Disease; SD, standard deviation. 
Additionally, given the difficulties regarding a thorough estimation of overall cost reduction per patient and per year by the use of Equoral, large multicenter studies including different health care systems and follow-up protocols appear warranted. However, the current study could initiate such analyses.

\section{Conclusion}

In our study in chronic stable HTx recipients, we retrospectively analyzed a 1:1 switch of Neoral to Equoral. We showed a safe interchangeability between Neoral and Equoral in a clinical routine setting of chronic HTx recipients, followed up at Heidelberg University Hospital regarding the occurrence of rejection episodes, routine laboratory, and survival. The $\mathrm{C} 0$ level and the DNL showed comparable values before and after the switch. No statistically significant differences regarding Neoral and Equoral doses were observed. We conclude that conversion to Equoral is effective and safe in chronic stable cardiac transplant recipients. However, due to a potential hazard to the patient, especially after HTx, multiple switches between the different generic immunosuppressants must be avoided, and close monitoring strategies and clear follow-up rules are obligatory. ${ }^{11}$

\section{Disclosure}

Andreas O Doesch received a research grant by Teva Pharmaceutical Industries Ltd. The authors report no other conflicts of interest in this work.

\section{References}

1. Borel JF. History of the discovery of cyclosporin and of its early pharmacological development. Wien Klin Wochenschr. 2002;114(12): 433-437.
2. Pollard S, Nashan B, Johnston A, et al; CONSENT: Consensus on Substitution in European Transplantation. A pharmacokinetic and clinical review of the potential clinical impact of using different formulations of cyclosporin A. Berlin, Germany, November 19, 2001. Clin Ther. 2003;25(6):1654-1669.

3. Vítko S, Ferkl M. Interchangeability of ciclosporin formulations in stable adult renal transplant recipients: comparison of Equoral and Neoral capsules in an international, multicenter, randomized, open-label trial. Kidney Int Suppl. 2010;(115):S12-S16.

4. Niemczyk M, Paczek L. Generic formulation of Cyclosporine A, Equoral $^{\circledR}$, in de novo kidney transplant recipients: five-year follow-up. Ann Transplant. 2011;16(2):59-62.

5. Billingham M, Kobashigawa JA. The revised ISHLT heart biopsy grading scale. J Heart Lung Transplant. 2005;24(11):1709.

6. Karapirli M, Kizilgun M, Yesilyurt O, et al. Simultaneous determination of cyclosporine A, tacrolimus, sirolimus, and everolimus in whole-blood samples by LC-MS/MS. ScientificWorldJournal. 2012;2012:571201.

7. Perlik F, Masri MA, Rost M, Kamarád V. Pharmacokinetic conversion study of a new cyclosporine formulation in stable adult renal transplant recipients. Biomed Pap Med Fac Univ Palacky Olomouc Czech Repub. 2005;149(2):309-313.

8. Maziers N, Bulpa P, Jamart J, Delaunois L, Eucher P, Evrard P. Correlations between cyclosporine concentrations at 2 hours post-dose and trough levels with functional outcomes in de novo lung transplant recipients. Transplant Proc. 2012;44(9):2880-2884.

9. Helderman JH, Kang N, Legorreta AP, Chen JY. Healthcare costs in renal transplant recipients using branded versus generic ciclosporin. Appl Health Econ Health Policy. 2010;8(1):61-68.

10. Knight SR, Morris PJ. The clinical benefits of cyclosporine C2-level monitoring: a systematic review. Transplantation. 2007;83(12): $1525-1535$.

11. Harrison JJ, Schiff JR, Coursol CJ, et al. Generic immunosuppression in solid organ transplantation: a Canadian perspective. Transplantation. 2012;93(7):657-665.
Drug Design, Development and Therapy

\section{Publish your work in this journal}

Drug Design, Development and Therapy is an international, peerreviewed open-access journal that spans the spectrum of drug design and development through to clinical applications. Clinical outcomes, patient safety, and programs for the development and effective, safe, and sustained use of medicines are a feature of the journal, which

\section{Dovepress}

has also been accepted for indexing on PubMed Central. The manuscript management system is completely online and includes a very quick and fair peer-review system, which is all easy to use. Visit $\mathrm{http}: / / \mathrm{www}$.dovepress.com/testimonials.php to read real quotes from published authors. 